\title{
FTIR and Energy Dispersive X-ray analysis of medicinal plants, Ocimum gratissimum and Ocimum tenuiflorum
}

\author{
P. Sakuntala ${ }^{1^{*}}$, R. Selva Raju ${ }^{2}$, Kaleem Ahmed Jaleeli ${ }^{3}$ \\ ${ }^{1}$ Department of Physics and Electronics, RBVRR Women's college, Narayanaguda, Hyderabad, TS, India \\ ${ }^{2}$ Physics section, FEAT, Annamalai University, Chidambaram, Tamil Nadu, India \\ ${ }^{3}$ Department of Physics, Nizam College, O.U., Hyderabad, T.S., India \\ *Corresponding Author: sakuntalap71@yahoo.com, Tel. : 919440357573
}

Available online at: www.isroset.org

Received: 12/May/2019, Accepted: 07/Jun/2019, Online: 30/Jun/2019

\begin{abstract}
Plant is an important source of medicine and plays a key role in world health. Vibrational and energy dispersive Xray spectra of leaves, stems and seeds from the two selected indigenous medicinal plants, Ocimum gratissimum and Ocimum tenuiflorum (family : Lamiaceae) have been studied with the help of FTIR and SEM-EDX. FTIR findings indicated the presence of characteristic functional groups like alkanes, alkenes, alkynes, alcohols, amides, amines, carboxylic acid, carbonyl compounds, carbohydrates (glycogen) and halogens. The results of SEM - EDX spectra have shown that the essential elements like Calcium, Magnesium, Copper, Zinc, Oxygen, Sodium, Iron, Selenium and Potassium were present in the selected medicinal plants. The obtained data will be helpful for making medicinal formulation and deciding dosage of the medicine made from these plants.
\end{abstract}

Keywords: Medicinal plants, FTIR, SEM-EDX, Ocimum gratissimum, Ocimum tenuiflorum.

\section{INTRODUCTION}

Although modern medicine is well developed in most of the world, large sections of the population in developing countries still rely on the traditional practitioners, medicinal plants and herbal medicines for their primary care. Moreover during the past decades, public interest in natural therapies has increased greatly in industrialized countries, with expanding use of medicinal plants and herbal medicines [1]. Plant synthesize hundreds of chemical compounds for functions including defence against insects, fungi, diseases and herbivorous mammals. Therefore, the analysis of these chemical constituents would help in determining various biological activities of plants [2]. Numerous phytochemicals with potential or established biological activity have been identified. Medicinal plants and herbs like turmeric, ginger, basil leaves, mint and cinnamon are commonly used in Indian dishes and they offer several health benefits. Cold and flu, relieve stress, better digestion, strong immune system and the list is simply endless. The secondary metabolites produced by the plants are usually responsible for the biological characteristics of plant species used throughout the world. The microbial growth in diverse situations is controlled by plant derived products. A variety of techniques can be used to determine and estimate the presences of phytoconstituents in medicinal plants. Spectroscopic technique is one of the most useful and popular tool used in the present study.

Basil is native to tropical regions from central Africa to Southeast Asia. It is a tender plant, and is used in cuisines worldwide. Ocimum gratissimum, also known as clove basil, African basil [3], and in Hawaii as wild basil [4], is a species of Ocimum in the family Lamiaceae. Ocimum tenuiflorum, commonly known as holy basil, tulasi or tulsi, is an aromatic perennial plant in the family Lamiaceae. It is native to the Indian subcontinent and widespread as a cultivated plant throughout the Southeast Asian tropics. Ocimum tenuiflorum is an annual or shortlived perennial plant that has been used as a culinary and medicinal herb for centuries. The species can grow in a variety of soil conditions, propagates by its small and numerous seeds, and grows rapidly. These plants have several medicinal values that depend on certain active chemical substances. These active chemical substances are believed to have physiological impact on the human body. 
Fourier Transform Infra Red spectroscopy is a method of obtaining infrared spectra by first collecting an interferogram of a sample signal using an interferometer, and then performing a Fourier Transform (FT) on the interferogram to obtain the spectrum. An FTIR Spectrometer collects and digitizes the interferogram, performs the FT function, and displays the spectrum. This method allows the analysis of a relevant amount of compositional and structural information in plants. Moreover, FTIR spectroscopy is an established time-saving method to characterize and identify functional groups [5]. Mineral elements though usually form a small portion of total combination of most plant materials and of total body weight; it was nevertheless treated as physiologically important particularly in body metabolism [6]. Trace elements play both curative and preventive role in combating diseases. There is a vast scope to exploit the preventive medicinal aspects of various trace elements such as $\mathrm{Ca}, \mathrm{K}, \mathrm{Mg}$, $\mathrm{Na}$ etc.

\section{RELATED WORK}

SEM-EDX and FTIR techniques have been employed to analyze the elements and functional groups of these medicinal plants, Ocimum gratissimum and Ocimum tenuiflorum. Different parts of the plants contain different elements in various concentrations.

\section{MATERIALS AND METHODS}

Sample collection: The leaves, stems and seeds of Ocimum gratissimum and Ocimum tenuiflorum plants were collected from CIMAP, Hyderabad and were washed with running tap water and then with distilled water. All materials were air- dried, cut into small pieces. The pieces were mechanically crushed and ground into powder. The powdered plant materials were kept at room temperature away from direct sunlight in closed dry plastic bags for further analysis.

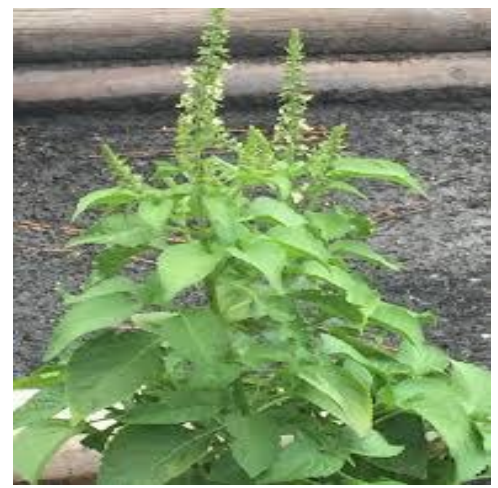

Fig. 1. Ocimum gratissimum plant

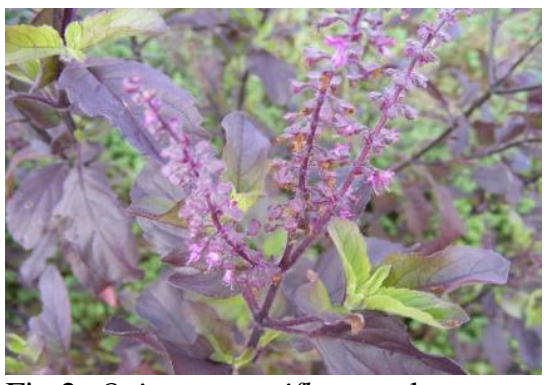

Fig.2. Ocimum tenuiflorum plant

Energy Dispersive X-ray Spectroscopy (EDX) Analysis Scanning electron microscopy is a powerful technique which allows evaluating morphological changes on the surface. When SEM is combined with EDX technique, it can provide valuable input in determining the distribution of various elements on the surface [7].The plant powder samples were subjected to the elemental analysis using Scanning Electron Microscope (SEM) with an energy dispersive $\mathrm{X}$-ray spectrometer (EDX).

\section{FTIR Spectral Analysis}

FTIR is the most powerful analytical tool for identifying the types of chemical bonds (functional groups) present in compounds. The wavelength of light absorbed is characteristic of chemical bond as can be seen in the annotated spectrum. Infrared spectra of powdered samples were recorded using Bruker alpha FTIR Spectrometer, between $4000-400 \mathrm{~cm}^{-}$, in the mid IR region.

\section{RESULTS}

\section{SEM-EDX analysis :}

The SEM -EDX spectra of the three parts of the selected medicinal plants were shown in figures 1-6. The results of the elemental composition were shown in table. 1 and they were represented graphically in figures 7 and 8. Calcium, Magnesium, Copper, Zinc, Oxygen, Sodium, Silicon, Chlorine, Iron, Selenium, Potassium and Carbon are present in the plants. The element, Oxygen is abundant in the leaves of both the plants, while $\mathrm{K}, \mathrm{Mg}, \mathrm{Cl}, \mathrm{Na}$ and $\mathrm{Ca}$ presented as moderate amount. $\mathrm{Ca}, \mathrm{K}$ and $\mathrm{Na}$ are presented as highest percentage in the stems of ocimum gratissimum, ocimum tenuiflorum and seeds of ocimim tenuiflorum respectively. But $\mathrm{Zn}, \mathrm{Br}, \mathrm{Fe}, \mathrm{Si}$ and $\mathrm{Se}$ presented only in trace quantities. Sodium and potassium are present in all the three parts of two selected plants.

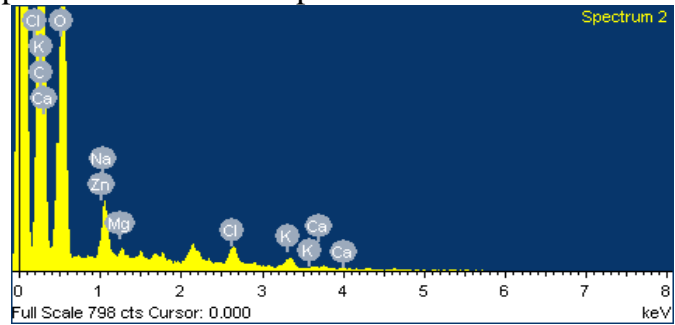

Fig 3 O-gratissimum leaf powder 


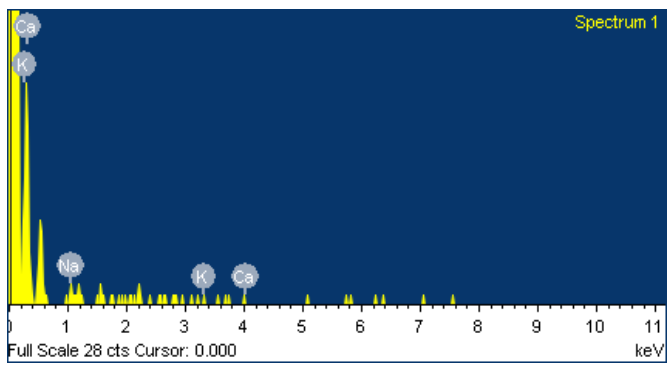

Fig 4 O-gratissimum stem powder

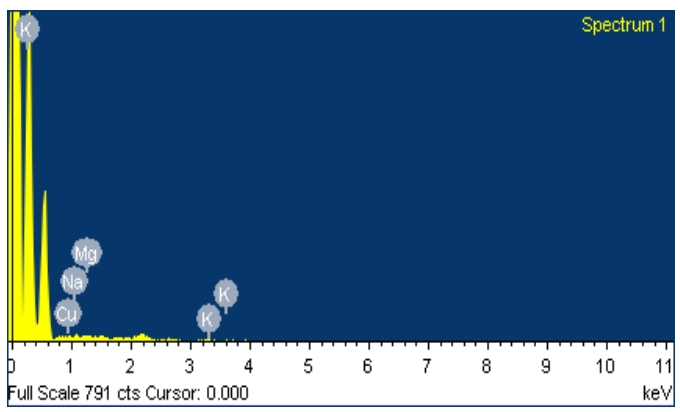

Fig 5 O-gratissimum seed powder

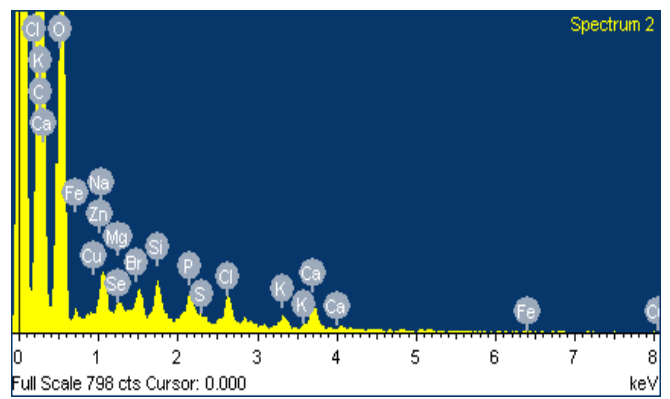

Fig 6 O-teniuflorum leaf powder

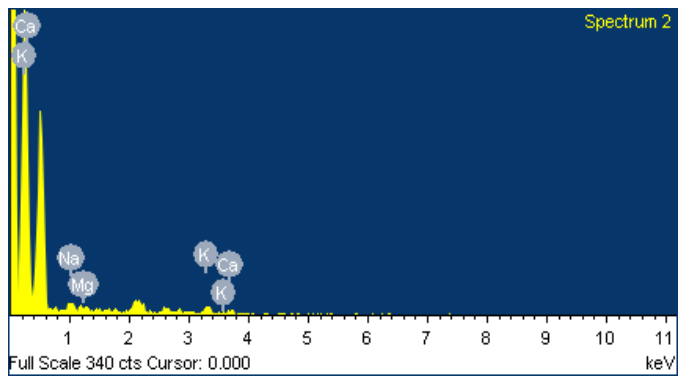

Fig 7 O-tenuiflorum stem powder

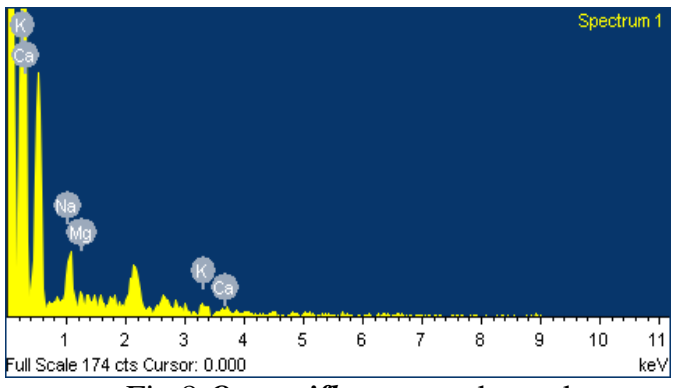

Fig 8 O-tenuiflorum seed powder
Table 1. Weight percentage of elements present in the three parts of the medicinal plants

\begin{tabular}{|c|c|c|c|c|c|c|}
\hline Botanic & \multicolumn{3}{|c|}{ Ocimum gratissimum } & \multicolumn{3}{|c|}{ Ocimum tenuiflorum } \\
\hline $\begin{array}{l}\text { Plant } \\
\text { part }\end{array}$ & $\begin{array}{c}\text { Leave } \\
\mathrm{s}\end{array}$ & $\begin{array}{l}\text { Stem } \\
\text { S }\end{array}$ & $\begin{array}{c}\text { Seed } \\
\mathbf{s}\end{array}$ & $\begin{array}{c}\text { Leave } \\
\text { s }\end{array}$ & $\begin{array}{c}\text { Stem } \\
\mathbf{s}\end{array}$ & $\begin{array}{c}\text { Seed } \\
\mathbf{s}\end{array}$ \\
\hline $\mathrm{Mg}$ & 1.79 & --. & 23.5 & 0.37 & 7.46 & 6.11 \\
\hline $\mathrm{Ca}$ & 5.6 & 66.61 & --- & 2.46 & 29.58 & 111.8 \\
\hline $\mathrm{Br}$ & --- & --- & --- & 2.06 & --- & --- \\
\hline $\mathrm{Cu}$ & 1.26 & --- & $\begin{array}{l}12.1 \\
7\end{array}$ & --- & $\begin{array}{l}-- \\
\end{array}$ & --- \\
\hline $\mathbf{Z n}$ & --- & --- & --- & 0.08 & --- & $-=-$ \\
\hline $\mathbf{O}$ & 68.83 & --- & --- & 40.23 & --- & $=--$ \\
\hline $\mathrm{Na}$ & 0.51 & 25.21 & $\begin{array}{l}30.1 \\
6\end{array}$ & 1.54 & 15.12 & $\begin{array}{l}47.9 \\
6\end{array}$ \\
\hline $\mathrm{Cl}$ & 10.48 & --- & --- & 2.11 & --- & --- \\
\hline $\mathbf{K}$ & 10.65 & 8.18 & $\begin{array}{l}33.5 \\
7\end{array}$ & 1.15 & 47.83 & $\begin{array}{l}34.1 \\
2\end{array}$ \\
\hline $\mathrm{Fe}$ & --- & --- & --- & 3.58 & --- & --- \\
\hline $\mathbf{C u}$ & --- & --- & --- & 45.15 & --- & $-=$ \\
\hline Si & --- & --- & --- & 1.49 & --- & --- \\
\hline Se & 0.88 & --- & --- & 0.33 & --- & $=--$ \\
\hline
\end{tabular}

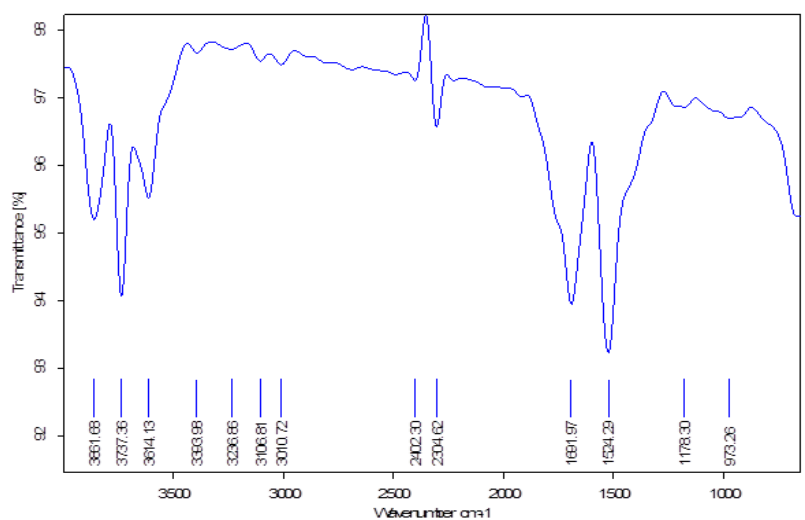

Fig-9 FTIR spectrum of $O$-gratissimum leaf powder

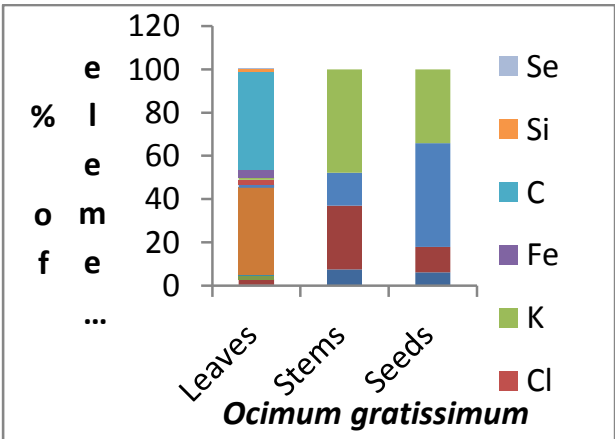

Figure 10 


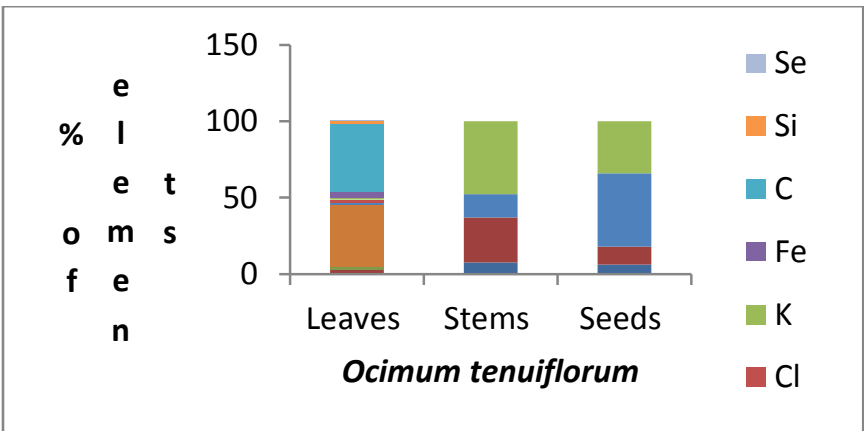

Figure 11

\section{FTIR analysis}

The FTIR spectra of plant parts like leaves, stems and seeds of selected medicinal plants are shown in figures 9 - 14. The FTIR findings indicated the presence of characteristic functional groups of alkanes, alkenes, alkynes, alcohols, amides, amines, carboxylic acid, carbonyl compounds, carbohydrates (glycogen) and halogen are present in the selected parts of the medicinal plants. . The absence of absorbance in between the region 2220-2260 cm- ${ }^{-1}$ indicates that there was no cyanide group in the parts of medicinal plants. This results show that the selected medicinal do not contain any toxic elements.

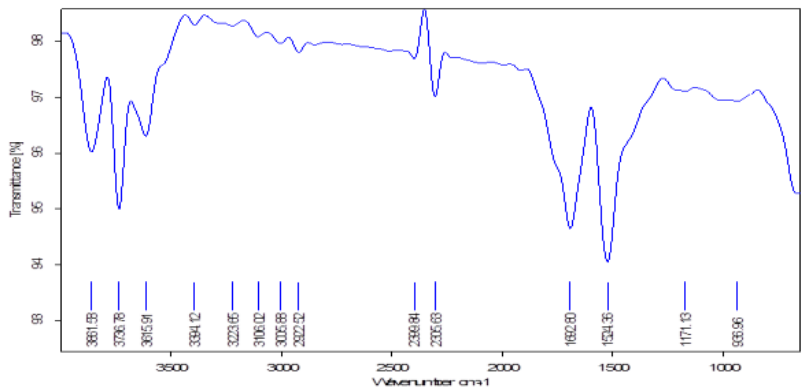

Fig 12 FTIR spectrum of $O$ - gratissimum stem powder

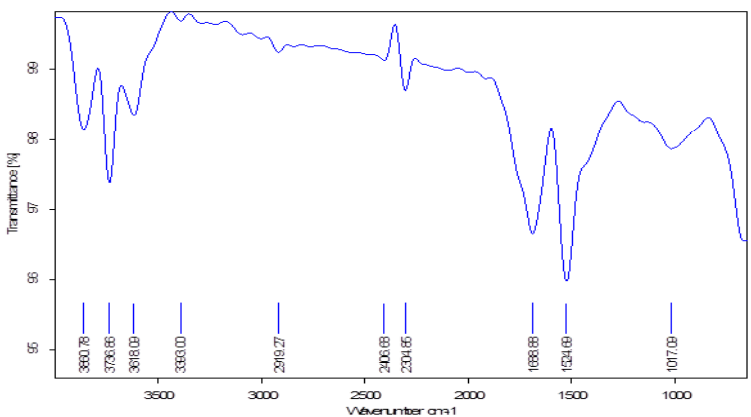

Fig 13 FTIR spectrum of $O$-gratissimum seed powder

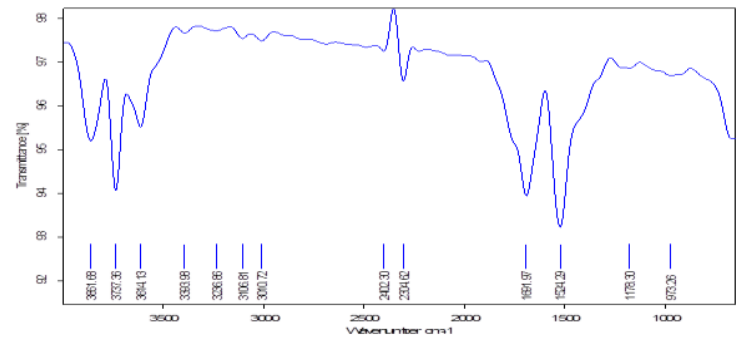

Fig-14 FTIR spectrum of O-tenuiflorum leaf powder

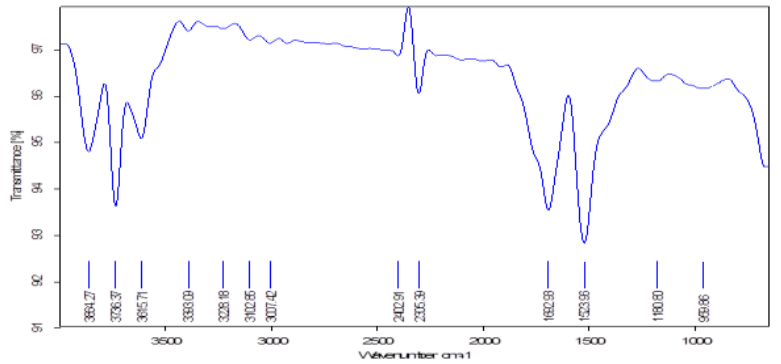

Fig-15 FTIR spectrum of $O$-tenuiflorum stem powder

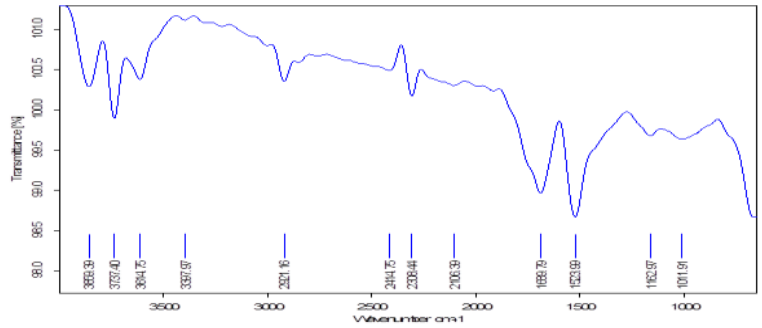

Fig-16 FTIR spectrum of O-tenuiflorum seed powder

\section{DISCUSSION}

Generally, Medicinal plants are being used in oriental medicine for treatment of ailment ranging from common cold to cancer [8]. Each element plays a number of different functions in the body. Zinc is a dietary mineral for humans and animals. Higher $\mathrm{Zn}$ intake protects people from cadmium poisoning while the symptoms of $\mathrm{Zn}$ overdose include vomiting, dizziness, fevers and diarrhea [9]. Copper is essential to all living organisms as a trace dietary mineral. The main areas where copper is found in humans are liver, muscle and bone. Copper compounds are used as bacteriostatic substance, fungicides and wood preservatives [10]. Copper has a number of important functions in the human body. It helps to produce red and white blood cells. Calcium is an important component of a healthy diet and a mineral necessary for life. It plays an important role in building strong and healthy bones and teeth both early and later in life [11]. Magnesium is essential to all living cells. Iron makes up part of many proteins in the body. It plays a vital role in many metabolic reactions. Selenium is an essential element required by plants and animals in trace quantities. Selenium is a powerful antioxidant that fights 
oxidative stress and helps defend the body from chronic diseases, such as heart disease and cancer. The body uses Sodium to control blood pressure and blood volume. Our body also needs sodium for our muscles and nerves to work properly. The health benefits of Potassium include relief from stroke, high blood pressure, heart and kidney disorders, and anxiety and stress. It helps enhance muscle strength, metabolism, water balance, electrolytic functions, and the nervous system. The selected plants contained all the above mentioned essential elements required for our body.

\section{CONCLUSION AND FUTURE SCOPE}

The presence of various characteristic functional groups like alkanes, alkenes, alkynes, alcohols, amides, amines, carboxylic acid, carbonyl compounds, carbohydrates (glycogen) and halogens are responsible for various medicinal properties of both plants. The aim behind the quantification of the elements is to highlight their potential efficacy against certain health conditions which occur mainly due to mineral deficiencies. The elements contained in these medicinal plants may play vital role in human nutrition. The high level of elements in these medicinal plants show that the leaves, stems and roots of the Ocimum gratissimum and Ocimum tenuiflorum plants will be helpful for making medicinal formulation and deciding dosage of the medicine made from these plants to cure diseases caused due to mineral deficiencies.

\section{AKNOWLEGMENTS}

I wish to extend my sincere thanks to my Respected Guide Dr. R. Selva Raju, Professor, Physics Section, FEAT, Annamalai University, Chidambaram, Tamil Nadu and my Co-Guide Dr. Kaleem Ahmed Jaleeli, Asst. Professor, Department of Physics, Nizam College, Osmania University , Hyderabad for providing unceasing encouragement, precious and erudite suggestions and directions, constant and untiring guidance along with the freedom of work that they gave me.

I would also like to extend my thanks to Central Research Laboratory (established under CPE grant) in R.B.V.R.R. Women's College, Hyderabad, Telangana State, India, for providing facilities and encouragement.

\section{REFERENCES}

[1]. WHO, (1998). Regulatory situation of herbal medicines. A worldwide review. Pp 1-5. Geneva, Switzerland.

[2]. Ragavendran P, Sophia D, Arulraj C, Starlin T and Gopalakrishnan VK. Evaluation of Enzymatic and Non- Enzymatic antioxidant properties of Aerva lanata (L)-An in vitro study. Int J Pharm Sci 2012; 4: 522-526.

[3]. PLANTS Profile for Ocimum gratissimum | USDA Plants, Retrieved Jan. 7, 2009.

[4]. Ocimum gratissimum - Wild Basil (Lamiaceae).
[5]. Grube M, Muter O, Strikauska S, Gavare M and Limane B. Application of FTIR spectroscopy for control of the medium composition during the biodegradation of nitro aromatic compounds. J Ind Microbiol Biotechnol 2008; 35: 1545-1549.

[6]. Hameed I, Dastagir G and Hussain F. Nutritional and elemental analyses of some selected medicinal plants of the family Polygonaceae. Pak J B 2008; 40: 2493-2502.

[7]. M. M. Figueira, B. Volesky, and H. J. Mathieu, "Instrumental analysis study of iron species biosorption by Sargassum biomass," Environmental Science and Technology, vol. 33, no. 11, pp. 1840-1846, 1999. View at Publisher. View at Google Scholar . View at Scopus.

[8]. Fisher C. Spices of life. Chemistry in Britain, 2002; $38: 40-42$.

[9]. Alloy BJ. Heavy metals in soils, John Wiley and Sons. Bud rot on oil palm plantations: Link to soil physical nutrient status. Better Crops International. 2003;2:22-5.

[10]. Fry RS, Ashwell MS, Lloyd KE, et al. Amount and source of dietary copper affects small intestine morphology, duodenal lipid peroxidation, hepatic oxidative stress and MRNA expression of hepatic copper regulatory proteins in weanling pigs. J Animal Sci.2012;90:3112-19.

[11]. R. Selva Raju, P.Sakuntala, Kaleem Ahmed Jaleeli, "Elemental status of medicinal plant-Moringa Oleifera", Journal of Applicable Chemistry, 2019, 8 (2): 491-495.

\section{AUTHORS PROFILE}

Mrs. P. Sakuntala is presently pursuing Ph.D ( Physics ) degree in Applied Spectroscopy from Annamalai University, Chidambaram, Tamil Nadu, India. Her main research work focuses on spectral studies on medicinal plants. She obtained her M.Sc. Physics with distinction from Nagarjuna University, Guntur, Andhra Pradesh and M. Phil., from Annamalai University, Chidambaram, Tamil Nadu, India.. She has published many research papers in a reputed, peer reviewed international Journals/Conferences and it's also available online. She is currently working as Asst. Professor and HOD in Department of Physics and Electronics from R.B.V.R.R. Women's College, Hyderabad since 2000. She has 20 years of teaching experience and 13 years of research experience.

Dr. R. Selva Raju is a Professor in the department of Engineering Physics, Faculty of Engineering and Technology, Annamalai University Annamalainagar Tamil Nadu. He has published many research papers in a reputed, peer reviewed international Journals/Conferences. $\mathrm{He}$ organized four national and one international conferences in the Department. He has guided so far Six Ph.D and twenty five M.Phil./M.E./M.Sc students and at present four students are working under him for $\mathrm{PhD}$. He has 16 years of teaching and research experience. He received best research paper award for his four research papers.

Dr. Kaleem Ahmed Jaleeli is an Asst. Professor in the department of Physics, Nizam College, O.U., Hyderabad. He has published more than fifty research publications in national and international journals. His area of research is Bio Physics and medical Physics.

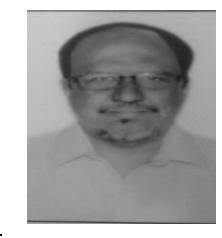

